\title{
How Different Are Students In Compulsory And Elective English Courses?
}

\author{
I-Chin Nonie Chiang
}

Foreign Language Center, National Chengchi University, Taiwan

Copyright $@ 2018$ by authors, all rights reserved. Authors agree that this article remains permanently open access under the terms of the Creative Commons Attribution License 4.0 International License

\begin{abstract}
Most Taiwanese universities and colleges offer a wide selection of English courses, compulsory or elective to cater to student needs. Compulsory courses are usually prerequisites for selective courses, except when students can prove an exceptionally high proficiency level with authenticated evidence, then the course can be waived and take selective courses immediately upon entering the college. Based on course objectives, elective courses are at a higher standard, or difficult, in terms of course goals, content, and tasks. Therefore, these courses can be compulsory basic English and selective advanced English. However, do students in these two kinds of courses really differ in terms of proficiency? If yes, to what extent do they differ? If this is truly the case, how should teachers deal with the situation of same level students but two different leveled courses? The results indicated that the participants in this study do not have significant differences in terms of vocabulary size and standardized tests. Therefore, the author offers some pedagogical advice based on the literature and their own experience and suggestions for future studies.
\end{abstract}

Keywords College English Course, TEFL, English Level of Tertiary Learners

\section{Introduction}

Being an English teacher in higher-level education in Taiwan for over 20 years, our observation is that nearly all the universities and colleges offer basic and compulsory English courses for freshmen in addition to advanced and elective English courses for others (hereafter basic English and advanced English). In terms of curriculum planning, these two types of courses have different course goals, as advanced English is more difficult than basic English. In other words, the advanced English requires a higher level of difficulty regarding the content and length of aural and written text, more complicated tasks, and longer oral and written output. In respect to online course goal announcement timing, teachers face two fundamental problems every year. First, the course website that contains all information, including themes, lesson plans, in-class activities, homework and assignments, projects, assessments, etc. must be available before the semester starts, so that students can plan their schedule accordingly. As a result, predicting student levels has become a challenging task for teachers since they have not even met the students yet. Secondly, even though the students of the university that we work for are comparatively more highly proficient than many other institutes, the departmental and individual differences are apparent. Therefore, while working on the syllabus and activity design, teachers must find activities and tasks that are easy to connect to other activities or to extend to projects. Teachers must have a lot of flexible content and backup plans when students do not respond to the original plan, i.e. the teacher can immediately improvise without boring the students. Since the course design also includes after-school assignments, to know student proficiency levels and their capabilities is of paramount importance in teaching.

After college entrance exam screening, our overall English level for freshman upon entering the university is around $80-100 \%$ of the General Scholastic Ability Test, roughly equivalent to CERF B1-C1 [1]. These freshmen must take a one-year basic English course. For the students whose proficiency is exceptionally high or who have experiences living abroad for a long time, they can get a waiver for basic English and take advanced English straight away. Finally, those who were less proficient can join a remedial class. After one-year basic English, the university offers a wide range of advanced English courses that emphasize different language skills for students who have needs and desires to train in a specific language skills, such as essay writing, academic listening, novel reading, movie appreciation, or oral training, etc. These advanced courses are intensive since they only last for one semester. Nonetheless, after the students enter university, their English proficiency levels are not consistently monitored. Does their proficiency level change? We argue that it is 'likely'. To what extent do 
they change? Do students who take advanced English have truly advanced knowledge more than those in basic English? Therefore, in this paper, we compare the vocabulary size and the General English Proficiency Test scores of these two types of English courses to see if one course is actually higher in terms of level than the other, and then we discuss what problems might occur. Finally, we provide some teaching advice for practicing teachers.

\section{Literature Review}

People read to obtain information, but the comprehension of the reading text is likely to be influenced by a reader's vocabulary size. To reach the proximal understanding of the text, a reader needs to know around $98 \%$ of the running text [2-3], which will require a learner to possess a rather large vocabulary bank, approximately 6,000-7,000 word families to understand range of spoken discourse and 8,000-9,000 for written discourse [4]. Or, at least, a reader would need to know around $95 \%$ of the running text to be able to understand the gist of a text. Even though research has clearly shown that vocabulary coverage is not the sole variable in influencing comprehension, it does play a major role [5, p. 64]. Based on Laufer and Ravenhorst-Kalovski [6], vocabulary knowledge accounted for $64 \%$ of the variance in reading comprehension scores. Therefore, the bigger the vocabulary size the better. McQuillan [5] reported that a non-native university level learner, who has a vocabulary size of 5,000-6,000, would suffice for academic demands. However, the vocabulary size of 6,000 word families covers $92.78 \%$, based on Nation [7]. That is, there will be 7 unknown words in 100 words, and on an average page of 300 words, there will be 21 unknown words, which seems likely to impact comprehension.

When a reader has a larger vocabulary size, their automation of the decoding process becomes rapid, which means they use the shortest time to process a series of stages of information passage in the brain. The readers can be said to possess large sight words, which means it only takes a short time for the reader to retrieve the word from memory, which speeds up reading [8]. In contrast, if a reader reads slow and spends a long time decoding of words, this somehow decreases comprehension. "Reading fluency consists of many component subskills, such as decoding, word recognition, phonological representation, and syntactic and semantic parsing or chunking, which are gradually automatized and utilized so that the reader's attention resources can focus on the higher level process of comprehension, analysis, and interpretation” [9, p. 19]. Therefore, a larger vocabulary leads to better comprehension, which leads to better performance on tests because most of the content is understood and information analyzed to obtain the best or most logical answer.
Learners with a large vocabulary should outperform their counterparts from a theoretical perspective; however, is this really the case in our classes? Is there a correlation between vocabulary size and proficiency scores? Are students different in nature in these two classes? These have baffled us for a while, because without these answers, we will have to keep on guessing every year while planning our lessons. The answers to these questions will help us plan better. Therefore, the purpose of this study is to investigate the differences between the two types of English courses in terms of vocabulary size and proficiency performance and discuss feasible solutions in teaching if the courses are found to have no significant differences. The study purpose is rephrased as research questions which are listed as follows:

1. What are the vocabulary sizes and GEPT scores of the students of basic English and advanced English?

2. Is there a significant difference between the vocabulary size and GEPT score of these two types of courses?

3. Is there a significant correlation between the vocabulary size and GEPT score of these two types of courses?

\section{Materials and Methods}

\subsection{Participants}

This present study took place at a national university in Taiwan and involved 3 intact classes of 2 types of English courses. Basic English was a year-long class, while advanced English was a semester class. Two classes of each type joined the study from the same academic year. After the college entrance exam screening, the students' overall English level when they entered the university was between $80-100 \%$ of the General Scholastic Ability Test, approximately equivalent to B1-C1 [1] according to the Common European Framework. Table 1 shows the details for the participants of this study.

Table 1. Participants of the two types of courses

\begin{tabular}{ccc}
\hline Basic English & \multicolumn{2}{c}{ Advanced English } \\
\hline Gender & Gender & Year \\
37 M (59.7\%) & $23 \mathrm{M} \mathrm{(31.9 \% )}$ & Year 1: $9(12.5 \%)$ \\
25 F (40.3\%) & $49 \mathrm{~F} \mathrm{(68.1 \% )}$ & Year 2: 36 (50.0\%) \\
Total: 62 & Total: 72 & Year 3: 31 (29.2\%) \\
& & Year 4: 6 (8.3\%) \\
& & Total: 72 \\
\hline
\end{tabular}

\subsection{Measures}

\subsubsection{Vocabulary Size Test}

The first data collected was participant vocabulary size. 
The measure was an online vocabulary size test hosted at VocabularySize.com (https://my.vocabularysize.com/). The data of the basic English course was collected at the $8^{\text {th }}$ week of the first semester. The test of the advanced English was administered at the $8^{\text {th }}$ week of the semester. Both tests were administrated in class to avoid dictionary use.

\subsubsection{GEPT}

Participants were asked to take the same mock test of high-intermediate-level General English Proficiency Test (GEPT) a month before the course ended. The test was developed by The Language Training and Testing Center in Taiwan and has been authenticated by many countries. The test has five levels (elementary, intermediate, high-intermediate, advanced, and superior) and each level has two stages. The first stage contains listening and reading sections, while the second stage writing and speaking. There are two reasons for using the reading section of the high-intermediate level. Firstly, the high-intermediate level was the closest to the B2 CEFR level, which reflected the participant entrance exam results. Secondly, the reading section contains 45 questions and the administration time was 50 minutes, which is the same length as a class period.

\subsubsection{Process and Analysis}

At the beginning of the semester, the author discussed the research idea with the participants. Then, before the vocabulary size test and GEPT data were collected, the author talked with the participants again and asked for their consent. After receiving consent from the students, the students took the two tests and the results were analyzed with SPSS.

\section{Results}

Regarding vocabulary size, the distribution of the two courses generally fits normal distribution and presents similar results as illustrated in Figure 1. Most of the participants clustered around 6,000 to 9,000. In the basic English class, $35.5 \%$ of the participants possessed 7,000-7,999 word families, $19.4 \%$ 8,000-8,999, and $16.1 \%$ 6,000-6,999. In the advanced English class, 31.9\% of the participants possessed 7,000-7,999 word families, 25\% $8,000-8,999$, and $18.1 \% 6,000-6,999$ as well as more than 9,000. The mean score for basic English was 7,438.71, standard deviation 1,357.717, minimum 4,100, maximum 10,600 , and the medium 7,450.00. The mean score of the advanced English was 7,811.11, standard deviation 1,213.487, minimum 4,100, maximum 10,500, and medium 7,750.00. Table 2 summarizes the statistical numbers to enhance the readability.

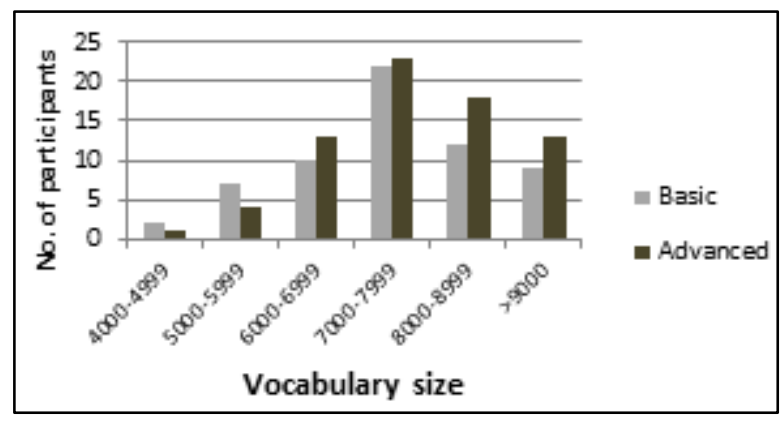

Figure 1. Distribution of participants (vocabulary size)

Table 2. Descriptive numbers of vocabulary size

\begin{tabular}{|c|c|c|c|c|c|c|c|}
\hline & & \multirow[b]{2}{*}{ Mean } & \multirow[b]{2}{*}{ S. D. } & \multicolumn{2}{|c|}{ Range } & \multirow[b]{2}{*}{ Medium } & \multirow[b]{2}{*}{ Mode } \\
\hline & & & & Minimum & Maximum & & \\
\hline \multirow{2}{*}{$\begin{array}{l}\text { Vocabulary } \\
\text { size }\end{array}$} & Basic & 7,438.71 & $1,357.717$ & 4,100 & 10,600 & 7,450 & 7,000 \\
\hline & Advanced & $7,811.11$ & $1,213.487$ & 4,100 & 10,500 & 7,750 & 6,700 \\
\hline
\end{tabular}

The GEPT results of the two courses also fit normal distribution but are slightly different. As illustrated in Figure 2, generally speaking, the distribution of the score pattern fits normal distribution. In the basic English class, most of the participants scored between 26-35 (48.4\% in total), while in the advanced class, most of the participants scored between 31-35 (33.3\%). The mean score of the basic class was 29.24 and the standard deviation 7.478 , while the mean score of the advanced class being 29.67 and the standard deviation being 7.283. Table 3 below summarizes the descriptive data.

Table 3. Descriptive numbers of GEPT

\begin{tabular}{|c|c|c|c|c|c|c|c|}
\hline & & \multirow[b]{2}{*}{ Mean } & \multirow[b]{2}{*}{ S. D. } & \multicolumn{2}{|c|}{ Range } & \multirow[b]{2}{*}{ Medium } & \multirow[b]{2}{*}{ Mode } \\
\hline & & & & Minimum & Maximum & & \\
\hline \multirow{2}{*}{ GEPT score } & Basic & 29.24 & 7.478 & 6 & 42 & 30 & 20 \\
\hline & Advanced & 29.67 & 7.283 & 2 & 43 & 31 & $24 / 32 *$ \\
\hline
\end{tabular}

*There are two modes: 24 and 32 both have 7 counts. 


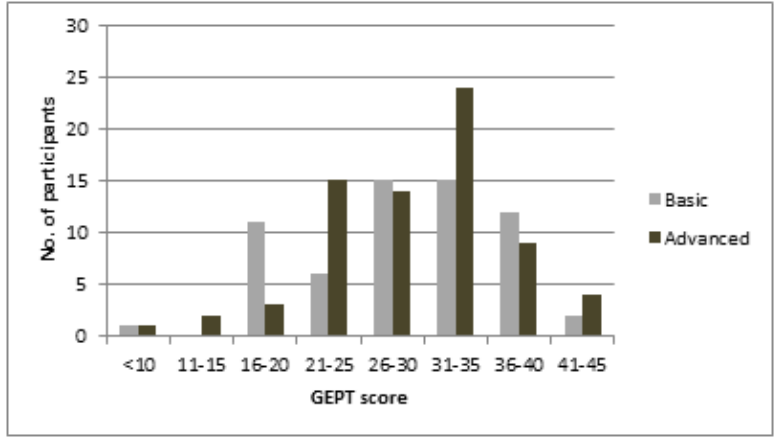

Figure 2. Distribution of participants (GEPT)

An independent sample t-test was run on the sample of 134 participants to see if there was a statistically significant mean difference between the two types of classes regarding vocabulary size and GEPT scores. Both tests showed no significant differences between the different courses (Vocabulary size: $\mathrm{t}=-1.676, \mathrm{df}=132$, $\mathrm{p}$ $=.429>.05$, n.s.; GEPT: $\mathrm{t}=-.332, \mathrm{df}=132, \mathrm{p}$ $=.453>.05$, n.s.).

Finally, through Pearson correlation test, a significant low correlation between the vocabulary size and the GEPT scores was found $(\mathrm{r}=.356, \mathrm{p}=.000<.01)$.

\section{Discussion}

To answer the first two questions, the vocabulary and GEPT results of the two types of courses showed similar patterns in the results in terms of mean, medium, and range with no significant differences; nonetheless, we see obvious individual variations (Figures 1 and 2). On the vocabulary size, the range was from 4,100 to 10,600 , with a mean of 7,438.71 for basic English and 7,811.11 for advanced English, while the medium was 7,450 and 7,750, respectively (Table 2). However, if we consider the modes of the two courses in comparison, the data showed that basic English had a higher number than advanced English (basic English 7,000 > advanced English 6,700, Table 2). As the research suggested, an average functioning EFL learner probably has around 5,000 to 6,000 word families to deal with school work [5]. The participant vocabulary sizes of the current study were as good as the research literature suggested, and probably slightly more, but the level of the vocabulary size seemed to freeze because no significant larger vocabulary size was observed from the advanced course; i.e. students are not expanding their vocabulary size after they enter university. As matter of fact, the smaller number of mode for the advanced course seemed to suggest that learners could be forgetting their vocabulary. Furthermore, Nation [2] pointed out that to reach the $98 \%$ of proximal comprehension condition, a learner needs 8,000 to 9,000 word families. In his calculation of the text coverage of each 1,000 word family, the level up to 6,000 word families only covers $92.78 \%$ (Table 4), while to the 7,000 , the coverages only becomes
93.22\%, which were still lower than the minimum 95\% coverage considered for general understanding [7].

Table 4. Coverage of text by a series of lists each containing 1,000 word families from Nation [7, p. 94, Table 7.1]

\begin{tabular}{|c|c|c|c|}
\hline $\begin{array}{c}\text { Vocabulary } \\
\text { level } \\
\end{array}$ & $\begin{array}{c}\text { Coverage } \\
\text { of text }\end{array}$ & $\begin{array}{c}\text { Accumulated } \\
\text { percentage }\end{array}$ & $\begin{array}{c}\text { Frequency } \\
\text { category }\end{array}$ \\
\hline $1^{\text {st }} 1,000$ & $75.22 \%$ & $75.22 \%$ & \multirow{5}{*}{$\begin{array}{c}\text { High-frequency } \\
\text { words }\end{array}$} \\
\hline $2^{\text {nd }} 1,000$ & $8.92 \%$ & $84.14 \%$ & \\
\hline $3^{\text {rd }} 1,000$ & $5.32 \%$ & $89.46 \%$ & \\
\hline $4^{\text {th }} 1,000$ & $1.71 \%$ & $91.17 \%$ & \\
\hline $5^{\text {th }} 1,000$ & $0.97 \%$ & $92.14 \%$ & \\
\hline $6^{\text {th }} 1,000$ & $0.64 \%$ & $92.78 \%$ & \multirow{5}{*}{$\begin{array}{c}\text { Mid-frequency } \\
\text { words }\end{array}$} \\
\hline $7^{\text {th }} 1,000$ & $0.44 \%$ & $93.22 \%$ & \\
\hline $8^{\text {th }} 1,000$ & $0.33 \%$ & $93.55 \%$ & \\
\hline $9^{\text {th }} 1,000$ & $0.24 \%$ & $93.79 \%$ & \\
\hline $10^{\text {th }} 1,000$ & $0.18 \%$ & $93.97 \%$ & \\
\hline $\begin{array}{c}11^{\text {th }} \text { to } 25^{\text {th }} \\
1,000\end{array}$ & $1.25 \%$ & $95.22 \%$ & \multirow[t]{2}{*}{$\begin{array}{c}\text { Low-frequency } \\
\text { words }\end{array}$} \\
\hline The rest & $5.42 \%$ & $100 \%$ & \\
\hline
\end{tabular}

The same individual variations also existed in the GEPT results (Figure 2). When the data was collected, we used more than two assessment to provide more objective results. Even though it would upgrade the design by also collecting data from other skills, for instance listening tests results, we decided not to because every year the university schedules a listening comprehension test for the basic English class and we do not want to overload learners with all these different assessments. In the end, we only collected the data that will most directly influence this study, i.e. the GEPT reading section. Passing for the high-intermediate level is to get around $60 \%$ answers correct, which is 27 correct answers out of the 45 questions. From the mean score of 27 in the current study, our participants were all probably at the right level, the high-intermediate level. But, let us remind the readers again, there was no significant difference in the two courses, which means, nearly no change was observed in their proficiency after the entrance exam. So, the question is why are the advanced course students not improving? And how do we get them to change? On the third research question, Pearson correlation analysis showed low degree correlation between the vocabulary size and the GEPT scores $(r=.356, \quad p=.000<.01)$. Therefore, a feasible beginning step for the change should be to add some more emphasis on vocabulary development.

Let us review the scenario here. Teachers were asked to design two different courses, while the advanced English must be more challenging than basic English in terms of content, tasks, and outputs (projects, presentations, or assignments), but basically student vocabulary size and test performance were nearly at the same level. What problems come out of this scenario? First, the learners of the advanced course may be forced to face really 
challenging readings and tasks. While the teachers followed the guidelines and gave more difficult assignments, students of lower levels may suffer from a failure of not completing the assignments and become upset and eventually surrender. Secondly, when the students could not follow the advanced course syllabus, the course was under the risk of being taken over by dominant students who have higher proficiencies, while other students will remain silent, a total unbalanced classroom. Next, when the pre-set target was unreasonably high or beyond student ability, the teacher feels disappointed, upset, and the students complain, which strongly influences how they interact or cooperate in the classroom. Therefore, to understand the real level of the students is really something that should be prepared and available for the teachers before they start new classes every year.

How can teachers design different courses for the students of similar levels, but one being more advanced than the other? What are the solutions? The following four points are our personal suggestions and something that we are personally going to add next year.

Table 5. The level of vocabulary [7, p. 96, Table 7.2]

\begin{tabular}{|c|c|c|c|}
\hline $\begin{array}{c}\text { Type of } \\
\text { vocabulary }\end{array}$ & $\begin{array}{l}\text { Number } \\
\text { of word } \\
\text { families }\end{array}$ & $\begin{array}{c}\text { Text } \\
\text { coverage }\end{array}$ & Description \\
\hline $\begin{array}{l}\text { High-frequency } \\
\text { words }\end{array}$ & 2,000 & $\begin{array}{c}88 \% \\
\text { including } \\
\text { proper } \\
\text { nouns etc. }\end{array}$ & $\begin{array}{l}\text { Words that occur } \\
\text { often in all kinds } \\
\text { of texts }\end{array}$ \\
\hline $\begin{array}{c}\text { Mid-frequency } \\
\text { vocabulary }\end{array}$ & 7,000 & $10 \%$ & $\begin{array}{c}\text { Words that occur } \\
\text { in a wide range of } \\
\text { texts }\end{array}$ \\
\hline $\begin{array}{c}\text { Low-frequency } \\
\text { vocabulary }\end{array}$ & 11,000 & $2 \%$ & $\begin{array}{l}\text { Words that do not } \\
\text { occur often in } \\
\text { most uses of the } \\
\text { language }\end{array}$ \\
\hline $\begin{array}{c}\text { Academic } \\
\text { vocabulary }\end{array}$ & 570 & $\begin{array}{l}10 \% \text { of } \\
\text { academic } \\
\text { texts }\end{array}$ & $\begin{array}{l}\text { Words that occur } \\
\text { often in a wide } \\
\text { range of academic } \\
\text { texts }\end{array}$ \\
\hline $\begin{array}{c}\text { Technical } \\
\text { vocabulary }\end{array}$ & 2,000 & $\begin{array}{l}20-30 \% \text { of } \\
\text { technical } \\
\text { texts }\end{array}$ & $\begin{array}{l}\text { Words that occur } \\
\text { most often in } \\
\text { specialist areas }\end{array}$ \\
\hline
\end{tabular}

\subsection{Add Vocabulary Size Test at the Beginning and the End of Each Semester}

In our observations, many students do not know how large their vocabulary size is because they are used to do what the teachers told them to do in high school. The teachers may provide vocabulary materials and then quiz them in class. So, they know some words, but they do know how many words they know. A vocabulary size test in the beginning of the semester can not only help students know their levels, but also provide valuable information for teachers to understand the whole class whether individually or together, not to mention the benefit of helping students set a clear goal. Student vocabulary size is dynamic, changing all the time, because vocabulary in the human brain is similarly controlled by a "use it or lose it" mechanism. So, our suggestion is that teachers and students get tested regularly on vocabulary size. We know that at least a few students think that they have a large vocabulary and they will not spend time memorizing vocabulary any more. They think they can only learn the words with the strategy of guessing from context. We disagree totally, because as Nation $[3,8]$ pointed out, vocabulary learning occurs through the deliberate learning through looking up the meanings of words in a dictionary.

\subsection{Add Academic Word List [10], PHRASal Expression List [4] and the Technical Vocabulary of the Students' Majors}

Many course books contain information on academic word lists. Nation [7, p. 96] summarized the type of vocabulary, number of word families, text coverage, and descriptions of the type in a table (Table 5). Apart from the more familiar high-frequency, mid-frequency, and low-frequency vocabulary, he added two types: academic vocabulary and technical vocabulary. Academic word list includes 570 word families $[7,10]$. If a learner is going to do academic study in English, they definitely need to learn the 570 word families on the academic word list $[7,10]$ because these words appear frequently across a wide range of academic texts and they are not in the first 2,000 words of English (high frequency words). The academic word list covers around $10 \%$ of the running words in an academic text. The PHRASal Expressions List (PHRASE List) was created and developed by Martinez and Schmitt [4]. Based on the importance of formulaic language in language acquisition [11, 12], Martinez and Schmitt created a list of 505 multiword items. In their belief, research studies starting from the general service list [13] and the academic word list, there needs to be a base for the theory when these word lists were compiled. Their lists should be based on the same base, "frequency". When they set the level at 5,000 word families (a consensus of the upper limit for high-frequency and the 5,000-word threshold finds independent validation in the literature from various sources, such as Capel [14], Hindmarsh [15], Milton [16], and Read [17]), they had a list of a total of 505 multiword items, which were also the most common formulaic sequences (approximately 10\% of the 5,000 most common word families). Moreover, their analysis also revealed that "the 505 words in the PHRASE List are almost entirely comprised of the top 2,000 words in English, with the vast majority in the top 1,000 (95\% in the first 1,000, 2.88\% in the second)" [4, p. 313]. Many learners, knowing all the separate words from the high-frequency level, may misunderstand the true meaning of the multiword items if they have not been taught or told the correct meaning of the phrase. We can 
see this often in output, both oral and written. Even though $10 \%$ is not alarmingly high, it is certainly not ignorable. The vocabulary size of these two-word lists have already been more than $10 \%$ of the 5,000 word families, with the technical vocabulary of 2,000 word families, we think that teachers should include the aforementioned vocabulary training and ask students to spend more time working on developing their vocabulary.

\subsection{Add Extensive Reading (ER) Programs}

After taking the vocabulary size test, students will know their own vocabulary size right away and we can take advantage of this by adding ER into the course [8]. Additive ER can be integrated into the course without changing the course, such as using it as extracurricular reading. This way, the students can choose graded readers or novels according to the vocabulary size and of their interest. One of the benefits of ER is that a teacher can set a class goal at the beginning and then help individuals to set their own goals [18]. Teachers can also help students through introducing different sources of free materials, e.g. MReader, XReading, mid-frequency graded readers from Paul Nation's website, and so on. These sites were mostly on graded readers, so students could choose their own reading based on their vocabulary size. Unfortunately, for the participants of the current study, graded readers could be too easy for most of them. However, if we look at this from another angle, while they read the graded readers and there were unknown words, then they must learn the words. If students wish to read more challenging texts than graded readers, the 8,000-word mid-frequency readers in Nation's website, and the young adult literature or even movie literature could be of their choice if they insist. In this case, they can use Lexile (https://fab.lexile.com/) to evaluate the difficult level before they start reading, to avoid inappropriate level and negative feelings of reading. For example, The Giver by Lois Lowry was shown around 760L on the website, with other novels of similar level on the sides of the page for reference, e.g. The Maze Runner by James Dashner (770L). On the page of The Maze Runner, there were useful information such as age range, vocabulary words section (up to 10 words in the book that are important for students to know) and "Find a Particular Reader", which can help estimate the comprehension level of a reader with specific Lexile. For instance, a 700L-student is estimated to understand $69 \%$ of the Giver. The page also anticipates what words may be difficult for readers, which is handy and user-friendly.

\subsection{Add Small Portion of Language-Focused Practices}

This is something that we would like to do from the next year. In the past, when we asked students what language skills they would like to improve the most, the answers were always vocabulary, spoken ability, and reading ability. Focus on form, which means to put attention on linguistic features in the context of communicative activities derived from a task-based syllabus or combination of the two [12], is not something we would emphasize since students told us that they had a lot of grammar practice in secondary schools and they do not want more. Therefore, except giving feedback on the occasions such as class written exercises, written assignments, or oral formal presentation, we seldom correct every grammatical error in the work, hoping not to sacrifice to accuracy. We write down the corrective feedback as notes and then give them out after. If it is a common error, we discussed it with the whole class. So, our confession is that we have not given any grammar classes for a long time. On the effectiveness of focus on form, the results are still inconclusive. Many consider focusing on form necessary, such as Ellis [12] and Schmidt [19]; while there are researchers who argue that some learning does not require attention, e.g. Williams [20]. But from our own teaching experiences, we feel that while student fluency increases, accuracy decreases. They paid little attention to the grammatical details. Their writing seemed too informal, like a mix of oral language and written language with a bit of texting mechanism. Therefore, we start feeling the need to add some language focus activities in our course. Surely it will not be a complete review of the basic rules, such as the present simple and present progressive, but we definitely take advantage of the peer-review exercise of the written homework to discuss it and explain the grammar at the same time. We will also throw a few dictations for them to try to write down the correct form. Finally, we would like to suggest that students really need to learn dictionary skills, so they can read example sentences and imitate how to use the words accurately.

The above four suggestions are based on the following considerations: Firstly, these activities can all be easily integrated into the existing course or simply used as homework. Secondly, these suggestions can help the teachers to help students set their individual goals or meet their individual needs. Thirdly, students can do these at their own pace. Finally, they can all help build schema for language acquisition. When a normal program added these four suggestions, the new program would satisfy most of Ellis' [12] 10 principles of instructed language learning, including instruction needs to ensure that learners develop both a rich repertoire of formulaic expressions and a rule-based competence, focus predominantly on meaning, focus on form, predominantly directed at developing implicit knowledge of the L2 while not neglecting explicit knowledge, require extensive L2 input, take account of individual differences in learners, and assess leaner proficiency regarding the examining both free and controlled production, i.e. 7 principles out of 10, which is good enough. If a teacher still has some space to fill, they can do an "enhanced ER" (cf. Song \& Sardegna [21]) or 
"ER Plus". They asked students to read outside of class, and discuss what they read inside the class, which is actually similar to Nation's linked skills activities and reading with discussion [3]. Doing so, we can add two more "opportunities for output" and "opportunity to interact in the L2", which leaves only "Principle 5: Instruction needs to take into account the learner's 'built-in syllabus." In terms of this, we think most of the trained teachers follow this "built-in syllabus", and the students at the tertiary level already learned most of the grammar, even the more advanced ones. Therefore, we think this as something that only needs to explained and reviewed when there is a need. Consequently, with these suggestions, we are able to follow the 10 principles over time.

\section{Conclusions}

Adding these four elements to a course does not influence the original teaching too much. The students should be able to work out a schedule to learn at their own pace; and the teacher simply monitors how they are doing. Depending on the weekly lesson is definitely not enough to increase proficiency. "It can be claimed with confidence that, if the only input students receive is in the context of a limited number of weekly lessons based on some course book, they are unlikely to achieve high level of L2 proficiency” [12, p. 218]. The job of a teacher is to plan, while most of the responsibility of learning is still on the learners. If learners know their own weaknesses, they can improve by self-study (cf. Chiang [22]), or find a study friend. Language learning has to be frequent and repetitive. Learners should ask questions immediately if they have them. For teachers, with this information, we know students better. For instance, if they perform poorly, we can look at our data to see if the level was too difficult? Is this a vocabulary problem? Grammar problem? Or is this an intelligent student who neglected to prepare? Are there other things they would like to do with interest? These questions are all waiting to be answered in the future.

Due to the limited resources, this study has limitations such as a small sample size and selected response to vocabulary size test and the GEPT test. Even though the instrument has a high level of validity and reliability, because the test format is still multiple choice, we cannot eliminate the possibility of lucky guesses. Therefore, future studies should consider adding free production as one of the instruments. In addition, the results of this study must be interpreted with caution and avoid overgeneralization. Future research could duplicate the study using students from different departments with a larger population for a more objective result. Finally, the test scores should collect the scores of other skills, e.g. listening, so that we can evaluate overall performance.

\section{REFERENCES}

[1] Council of Europe. Common European Framework of Reference for Languages: Learning, teaching, assessment, Cambridge University Press, Cambridge, 2001.

[2] P. Nation. How large a vocabulary is needed for reading and listening? The Canadian Modern Language Review, Vol.63, No.1, 59-82, 2006.

[3] P. Nation. Designing reading tasks to maximize vocabulary learning, Applied Research on English Language, Vol.3, No.1, 1-8, 2013b.

[4] R. Martinez, N. Schmitt. A Phrasal Expressions List, Applied Linguistics, Vol.33, No.3, 299-320, 2012.

[5] J. McQuillan. What can readers read after graded readers? Reading in a Foreign Language, Vo.28, No.1, 63-78, 2016.

[6] B, Laufer, B. Ravenhorst-Kalovski. Lexical threshold revisited: Lexical text coverage, learner's vocabulary size and reading comprehension, Reading in a Foreign Language, Vol.22, 15-30, 2010.

[7] P. Nation. What should every EFL teacher know? Compass Publishing, Korea, 2013a.

[8] P. Nation. Principles guiding vocabulary learning through extensive reading, Reading in a Foreign Language, Vol.27, No.1, 136-145, 2015.

[9] J. Huffman. Reading rate gains during a one-semester extensive reading course, Reading in a Foreign Language, Vol.26, 17-33, 2014.

[10] A. Coxhead. A new academic word list, TESOL Quarterly, Vol.34, 213-238, 2000.

[11] F. Myles. From data to theory: the over-representation of linguistic knowledge in SLA, Transactions of the Philological Society, Vol.102, 139-168, 2004.

[12] R. Ellis. Principles of instructed language learning, System, Vol.33, 209-224, 2005.

[13] M. West. A General Service List of English Words, Longman, Green and Co., 1953.

[14] A. Capel. A1-B2 vocabulary: insights and issues arising from the English Profile Wordlists project, English Profile Journal, Vol.1, No. e3, 1-11, 2010.

[15] R. Hindmarsh. Cambridge English Lexicon, Cambridge University Press, England, 1980.

[16] J, Milton. Measuring Second Language Vocabulary Acquisition, Multilingual Matters, England, 2009.

[17] J. Read. Assessing Vocabulary, Cambridge University Press, England, 2000.

[18] F. Stoller. Viewing extensive reading from different vantage points, Reading in a Foreign Language, Vol.27, No.1, 152-159, 2015.

[19] R. Schmidt. Deconstructing consciousness in search of useful definitions for applied linguistics, AILA Review, 
Vol.11, 11-26, 1994.

[20] J. Williams. Learning without awareness, Studies in Second Language Acquisition, Vol.27, 2, 2005.

[21] J. Song, V. G. Sardegna. EFL Learners' Incidental Acquisition of English Prepositions through Enhanced
Extensive Reading Instruction, RELC, Vol.45, No.1, 67-84, 2014.

[22] I. N. Chiang. Autonomous Learning and Principles for Deep Knowledge, Linguistics and Literature Studies, Vol.6, No.1, 27-34, 2018. 